\begin{tabular}{c|c|c}
\hline \hline $\begin{array}{c}\text { Vol. 34(1):29-35 } \\
\text { http://dx.doi.org/10.4217/OPR.2012.34.1.029 }\end{array}$ & Ocean and Polar Research & March 2012 \\
\hline \hline
\end{tabular}

\title{
Article
}

\section{Relationship between Interannual Variability of Phytoplankton and Tropical Cyclones in the Western North Pacific}

\author{
Jong-Yeon Park ${ }^{1}$, Jong-Seong Kug ${ }^{1 *}$, Jisoo Park², and Chan Joo Chang ${ }^{1}$ \\ ${ }^{I}$ Climate Change \& Coastal Disaster Research Department, KORDI \\ Ansan P.O. Box 29, Seoul 425-600, Korea \\ ${ }^{2}$ Korea Polar Research Institute, KORDI \\ Incheon 406-840, Korea
}

\begin{abstract}
We investigated the interannual relationship between chlorophyll concentrations in the western North Pacific and tropical cyclones (TCs) in the western North Pacific by analyzing data collected for $>12$ years. Despite the short-term scale (2 3 weeks) in the contribution of tropical cyclones to phytoplankton, the current study revealed that the long-term chlorophyll variability in the western North Pacific is profoundly related to long-term variability in the frequency of TCs. It was also found that the Pacific decadal oscillation (PDO) tends to control such relationships between the 2 bio-physical systems. This result suggests a significant climatic relationship between TC activity and marine phytoplankton, and also suggests the possibility of more accurate estimations of primary production in the western North Pacific.
\end{abstract}

Key words : phytoplankton, chlorophyll, tropical cyclone, Western North Pacific

\section{Introduction}

A tropical cyclone (TC), also known as a typhoon or a hurricane, is one of the most devastating natural phenomena in terms of loss of life and economic damage. Besides its dramatic effect on humans, it also impacts marine phytoplankton, which is an important factor for proper functioning of the marine ecosystem and fisheries (Subrahmanyam et al. 2002; Lee and Niiler 2003; Babin et al. 2004; Zheng and Tang 2007). This is because a TC causes disruption of the upper ocean and pumps the nutrient-rich subsurface water into the surface levels (Hazelworth 1968; Sanford et al. 1987; Walker et al. 2005). TCs are acknowledged to be an important event for the injection of nutrients into the euphotic layer and for enhancement of phytoplankton, in addition to producing oceanic mesoscale eddies or Rossby waves (McGillicuddy et al. 1998; Uz et al. 2001; Lin et al. 2003; Son et al. 2006).

\footnotetext{
*Corresponding author. E-mail : jskug@kordi.re.kr
}

Since the availability of remote sensing, many studies have investigated the influence of TCs on phytoplankton. For example, Babin et al. (2004) showed that a decrease in temperature and an increase in chlorophyll concentration could last for 2-3 weeks after the passage of a TC. Lin et al. (2003) suggested that the contribution of TCs to annual new biomass production in the South China Sea may be 20-30\%. By analyzing the ocean color data from satellites and in situ data, Son et al. (2006) and Zhao et al. (2009) also indentified phytoplankton blooms triggered by typhoons Megi and Nuri, respectively.

However, most studies on the relationship between TCs and ocean biology have been confined to case-study research examining a specific typhoon in a specific local domain, and have focused on short-term variability. The relationship between TCs and the variability of phytoplankton on a long-term scale remains unexplored. This relationship is important for understanding the long-term variabilities which occur in marine biology, the bio-physical coupling in climate studies, and for estimating amounts of physically induced phytoplankton. This could be particularly true in 
the Western North Pacific (WNP) region where the activity of TCs is strong, and thus TC-induced biological production can significantly contribute to the annual primary production.

In this study, we approached the issue regarding the long-term relationship between the two fields. By analyzing 3-month smoothed data (sub-seasonal signal removed), the long-term variability of chlorophyll concentration associated with that of TC passage frequency was investigated. In addition, the underlying climatic phenomenon associated with such long-term variability was also addressed.

\section{Data and methods}

Phytoplankton biomass is commonly inferred from the measurement of chlorophyll concentrations. We used satellite-derived chlorophyll concentration data obtained from 2 ocean color sensors, the Sea-viewing Wide Fieldof-view Sensor (SeaWiFS) and the Moderate Resolution Imaging Spectroradiometer (MODIS) from Goddard Space Flight Center, which provide global, multi-year data concerning marine phytoplankton (Esaias et al. 1998; McClain et al. 1998). These ocean surface chlorophyll data are monthly level-3 datasets binned to a regular spatial grid of $9 \mathrm{~km}$. To determine computational efficiency and global-scale variability, when necessary, the data were interpolated into a $2.5^{\circ}$ by $2.5^{\circ}$ gridded resolution. Ocean chlorophyll concentrations tend to show a lognormal distribution (Campbell 1995), therefore, we used the median value in each gridded region for the bilinear interpolation. These data covered a period from September 1997 to December 2009 (SeaWiFS from September 1997 to December 2007, MODIS from January 2008 to December 2009).

Typhoon track data used in this study was the best track data issued by the Regional Specialized Meteorological Center (RSMC), and described the location of the cyclone center every 6 hours. Passage frequency was constructed by counting the number of TCs passing through each grid box $\left(2.5^{\circ}\right.$ by $\left.2.5^{\circ}\right)$ and then performing a 9-grid smoothing with surrounding 8 grids. This was a method similar to that used to define the passage frequency of TCs in previous studies (Kim et al. 2005; Kwon et al. 2007).

We also used the SST from the Extended Reconstructed Sea Surface Temperature version 3 (ERSST.v3) dataset (Smith et al. 2008) created by the National Climatic Data Center (NCDC) of the National Oceanic and Atmospheric Administration (NOAA). This dataset has a monthly time resolution and a $2.0^{\circ}$ spatial resolution, which are defined as individual observations averaged onto a $2^{\circ}$ grid.

All data used in the current study were monthly-mean data (not seasonal-mean data) obtained after the removal of seasonal cycles. For the analysis of long-term variability, the data were smoothed for a 3-month period. The typhoon season investigated in this study ranged from July to November, when the typhoon activity during a year is strongest.

\section{Results}

TCs can cause the bloom of oceanic phytoplankton by entrainment mixing and upwelling, which lasts to 2-3 weeks after the passage of a cyclone. Hence, one could expect a positive relationship between TC frequency and chlorophyll concentration within the period of the TC effect. Before investigating the relationship between the chlorophyll and TCs on a long-term time scale, we first checked whether 2 datasets exhibited this positive relationship. An example month, when $>7$ TCs occurred within one year occur is shown in Fig. 1. Although TC passage does not always produce positive chlorophyll anomalies, possibly due to the response of chlorophyll during and subsequent to TC passage, or the influence of other factors on chlorophyll, the figure shows a general increase in chlorophyll along the TC track. It is notable that although the time-scale of the TC effect on ocean biology is less than one month, the enhancement of biological activity along the TC tracks also appears in this monthly mean data.

As shown in Fig. 1, the biological response along the

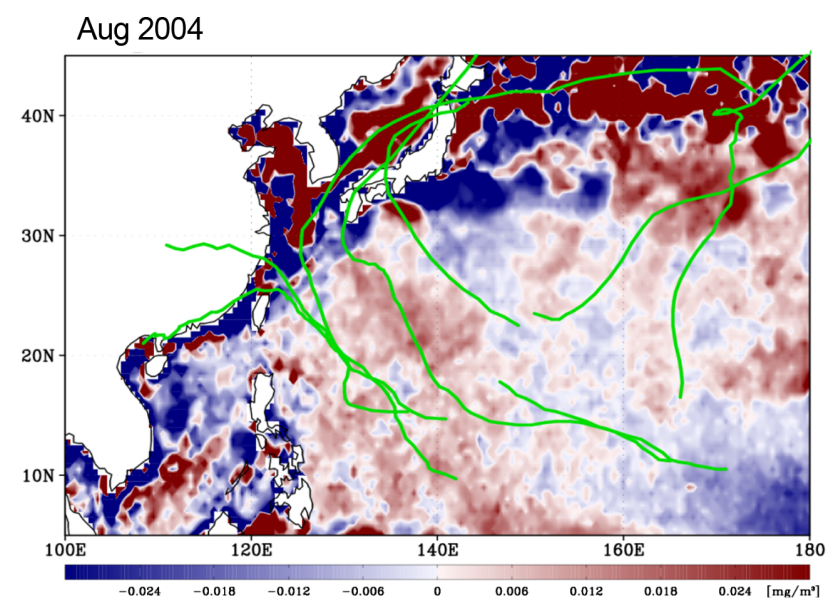

Fig. 1.Tracks of tropical cyclones (bold lines) and monthly mean anomalies of chlorophyll concentration (shadings) during August 2004 


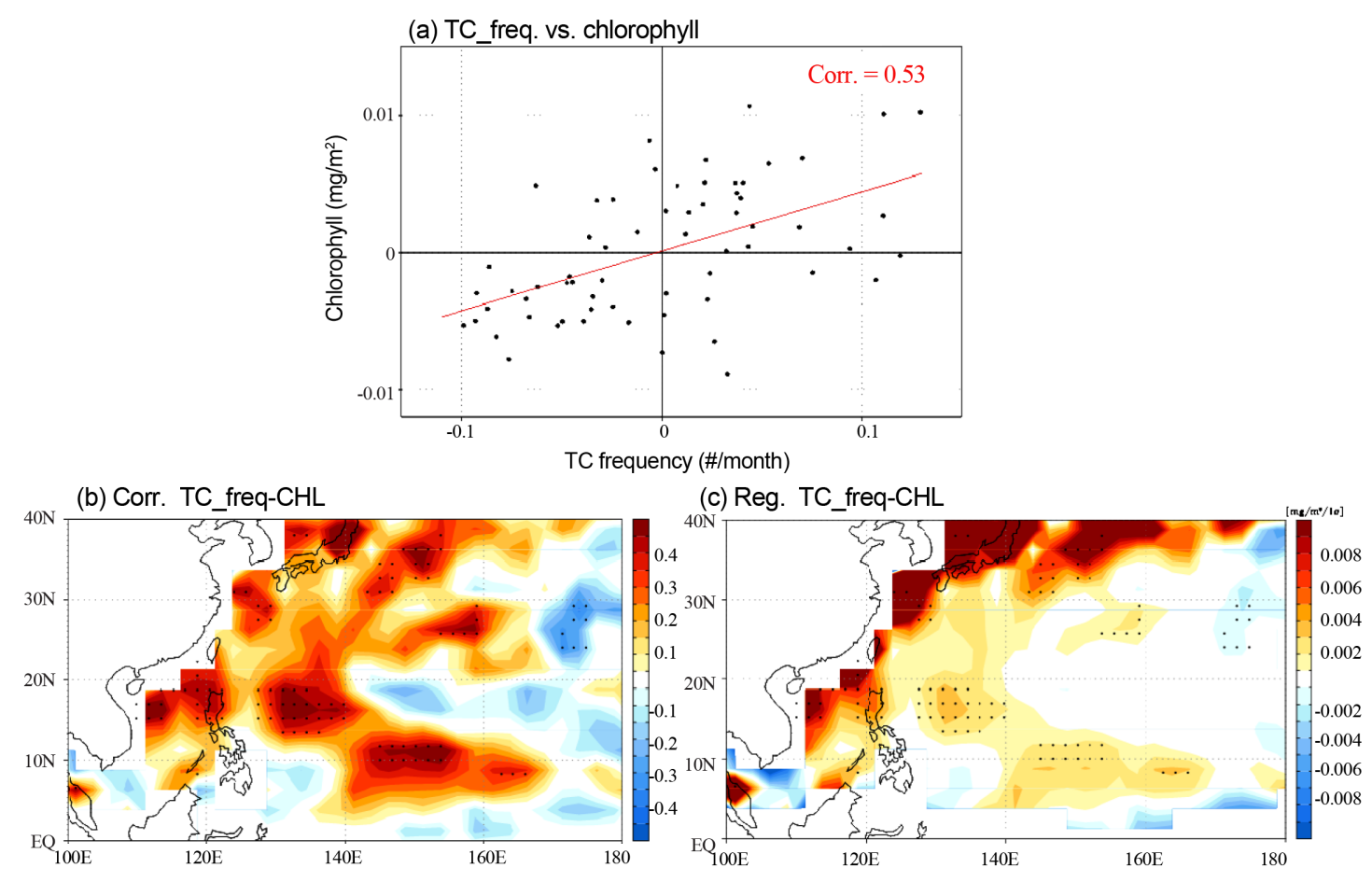

Fig. 2. (a) Scatter plots of the same 2 variables averaged in the western North $\operatorname{Pacific}\left(5^{\circ} \mathrm{N}-40^{\circ} \mathrm{N}, 1^{\circ} \mathrm{E}-170^{\circ} \mathrm{E}\right)$. $\mathrm{The}^{\circ}$ value at the right upper corner is the correlation coefficient between $\mathrm{TC}$ frequency and chlorophyll concentration. (b) Correlation map and (c) regression map between the passage frequency of tropical cyclones and chlorophyll concentration. Stippled area denotes the $95 \%$ confidence region

TC track is much stronger in coastal regions and higher latitudes than in the open sea. This is because the transport of suspended sediment from the river, as well as mixing and upwelling, can trigger a stronger phytoplankton bloom in coastal regions (Zhao et al. 2009). Additionally, the response of phytoplankton to TCs may also be more pronounced in higher latitude regions where the mixed layer depth dramatically fluctuates due to the climatological conditions of the ocean and atmosphere (Moore and Abbott 2000). These strong phytoplankton responses to TCs near the coastal regions and in higher latitudes can be found in the regressed filed between the 2 variables (Fig. 2c).

The next question was whether this relationship between the biological and physical systems would be found over a long-term period in the WNP basin. Fig. 2a shows a scatter plot of anomalous TC passage frequency versus chlorophyll concentration averaged in the Western North Pacific $\left(5^{\circ} \mathrm{N}-40^{\circ} \mathrm{N}, 130^{\circ} \mathrm{E}-170^{\circ} \mathrm{E}\right)$; note that the seasonal cycle was removed from the data. There is a positive correlation between TC frequency and chlorophyll concentration. The correlation (0.54) was significant at the $95 \%$ level. This indicates that the increase in TC frequency over the WNP is related to a significant increase in the basin-wide phytoplankton biomass on a seasonal-mean time scale, which is much longer than the timescale of TCs and the corresponding biomass lifetime. This result implies that even in the long-term scale, the pumping effect produced by TCs on the increase of phytoplankton is a crucial factor for the total variability of phytoplankton in the WNP. This is because a single TC can trigger a $>30$-fold increase in surface chlorophyll concentration (Lin et al. 2003). Therefore, the long-term variability of basin-wide phytoplankton, which can be utilized in a marine ecosystem or fishery, possibly can be estimated by variability of TCs.

Fig. $2 b$ shows a map correlating 3-month smoothed TC frequency with chlorophyll data. It also indicates that a significant positive relationship exists between these 2 variables, particularly in the region where TCs occur. This local positive correlation, which is distributed over the WNP, could be the basis of the basin-wide positive relationship shown in Fig. 2a. A quantifiable relationship was also derived from the regressed map between TC frequency and chlorophyll. As indicated in Fig. 2c, the increase in chlorophyll concentration was $\sim 0.003 \mathrm{mg} / \mathrm{m}^{3}$ per one standard deviation of TC frequency in the open sea, while it is was $>0.01 \mathrm{mg} / \mathrm{m}^{3}$ near the coastal region. 
(a) Corr. TC_freq-CHL (JAS)

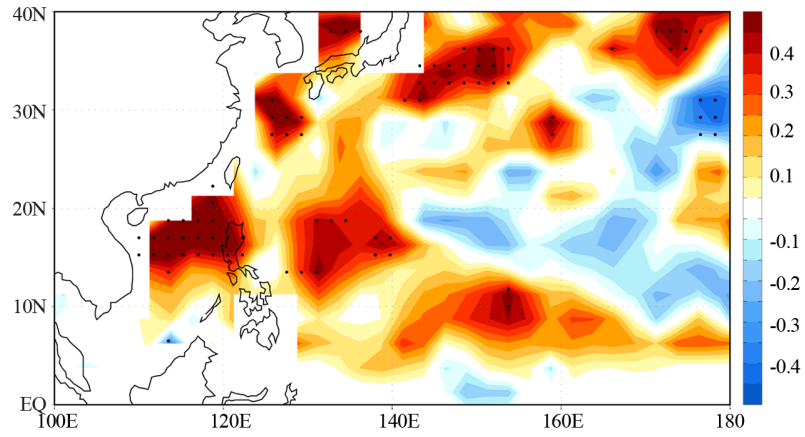

(b) Corr. TC_freq-CHL (SON)

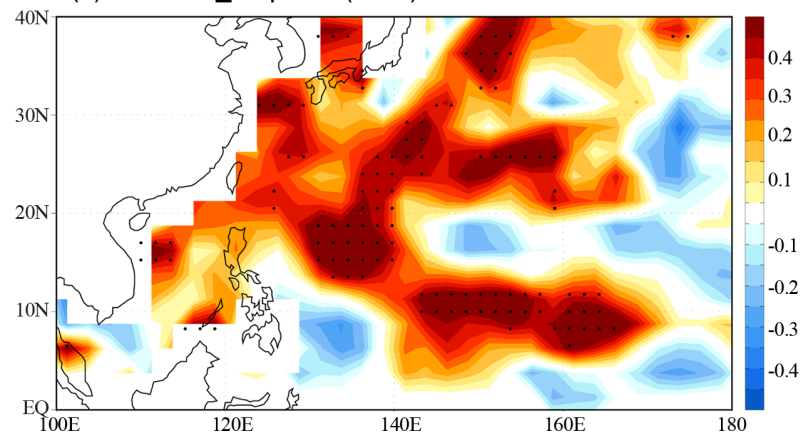

Fig. 3. Correlation maps between the passage frequency of tropical cyclones and the chlorophyll concentrations during (a) JAS (July-August-September) and (b) SON (September-October-November). Stippled area denotes the $95 \%$ confidence region

Again, these results also show that TCs can have a significant effect on the variability of chlorophyll, even during an extended time-period.

When the analyzed time period (July-August-SeptemberOctober-November) was separated into 2 sub-periods consisting of JAS (July-August-September) and SON (September-October-November), the same local correlations between TC frequency and chlorophyll concentration were found (Figs. 3a and 3b, respectively). The result generally shows a positive correlation between TC frequency and chlorophyll concentration during both periods. Although the correlation results of the 2 subperiods exhibited similar patterns, the relationship was stronger during the latter period. This change could possibly result from different basic states of bio-physical fields in the WNP or seasonal characteristics of typhoon activity during the 2 sub-periods. A more detailed analysis needs to be conducted to completely understand the cause of this difference.

The above results showing a positive relationship between TCs and chlorophyll are deeply associated with ocean's response to TC passage. The role of TCs on the (a) Corr. TC_freq-SST

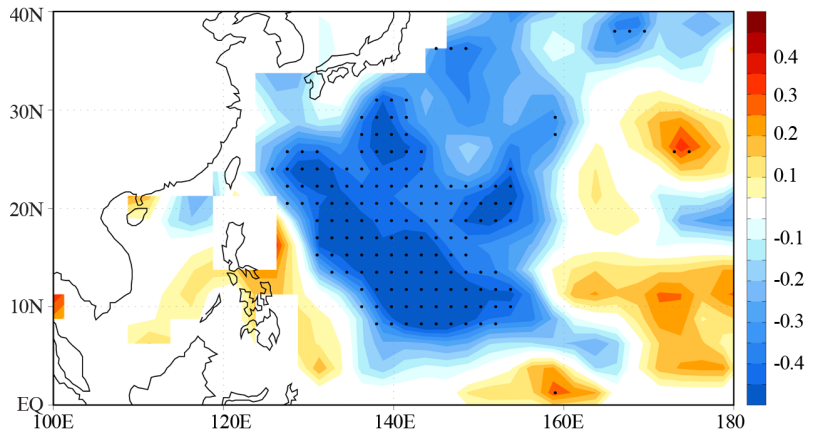

(b) Corr. CHL-SST

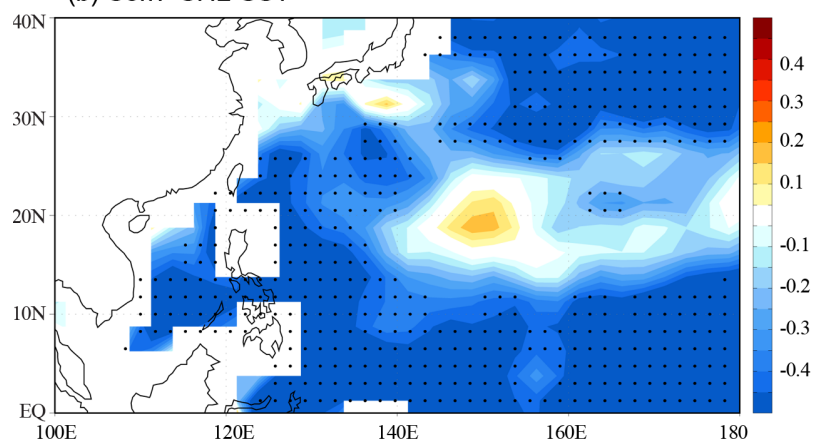

Fig. 4. Correlation maps (a) between the passage frequency of tropical cyclones and the SST and (b) between the chlorophyll concentration and the SST. Stippled area denotes the $95 \%$ confidence region

ocean is well documented in previous studies (Hazelworth 1968; Dickey and Simpson 1983; Stramma et al. 1986). The cyclonic system of TCs produces Ekman pumping, shear-induced entrainment mixing, and the deepening of mixed layers. Such oceanic responses involve the transport of cold, nutrient-rich subsurface water to the surface, consequently inducing positive anomalies of chlorophyll concentration.

Correlation maps of SST with TC frequency and chlorophyll shown in Fig. 4 illustrate that such mechanisms are valid in the long-term scale. Fig. $4 \mathrm{a}$ indicates the decrease of SST with TC passage, especially in the region where TCs frequently pass over $\left(130^{\circ} \mathrm{E}-160^{\circ} \mathrm{E} ; 5^{\circ} \mathrm{N}-30^{\circ} \mathrm{N}\right)$. Fig. 4 displays the SST cooling effect of TCs produced by the upwelling of subsurface cold water. Upwelling of subsurface water typically accompanies the increase of chlorophyll due to the increase of nutrient supplies, thus the SST and chlorophyll are negatively correlated with each other (Fig. 4b). Therefore, these results could provide an explanation for the positive correlation between chlorophyll and TC frequency shown in Fig. 2. The point we would emphasize is that such mechanisms 
(a) CHL SVD1

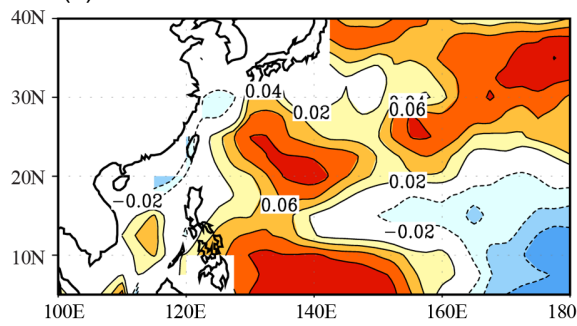

(b) TC_freq SVD1

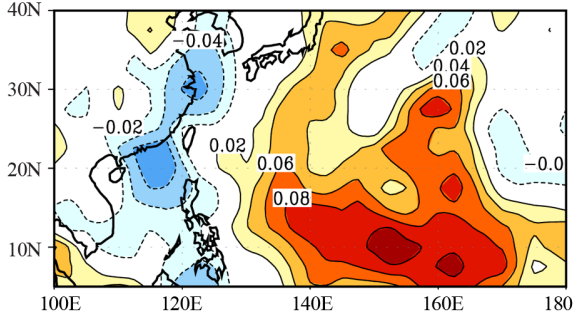

(c) Expansion Coeff. (38.5\%)

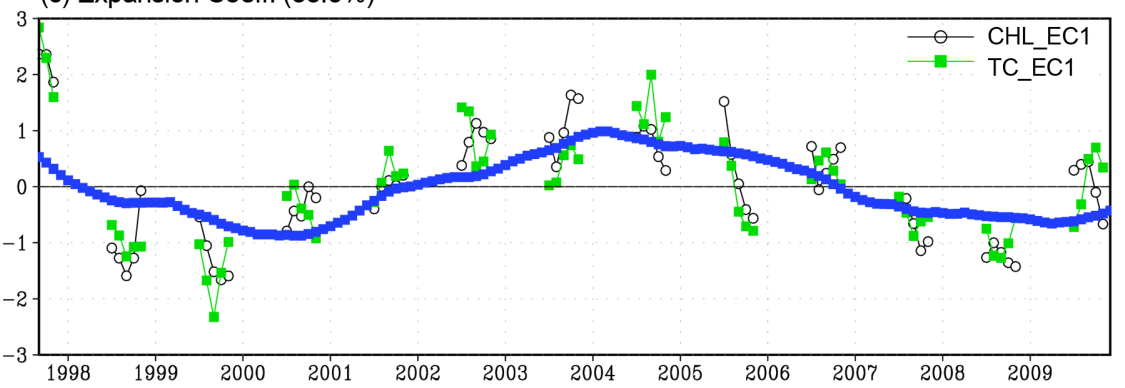

Fig. 5. Co-variability modes of (a) the chlorophyll concentration and (b) the passage frequency of tropical cyclones for 5 months (July to November) during the period 1997-2009. (c) Corresponding expansion coefficients of the 2 modes. The bold line represents the 3-year running mean of PDO index

are available even in the long-term scale.

Additionally, the co-variability of TC and phytoplankton in the WNP was evaluated using singular vector decomposition (SVD) analysis. Figs. 5a-5c show the first co-variability modes of chlorophyll and TC, and their corresponding time series. In general, chlorophyll variability seems to be associated with the variability of TC passage, particularly in the region west of line $160^{\circ} \mathrm{E}$, where TC passage often occurs. For example, the TC increase between lines $130^{\circ} \mathrm{E}$ and $160^{\circ} \mathrm{E}$ is somewhat related to the increase in chlorophyll. This result is consistent with the above result concerning the interannual relationship between the 2 fields. However, this relationship may not occur or be totally opposite in the region east of line $160^{\circ} \mathrm{E}$. This inconsistency in the Far East could be related to the region having a lower TC frequency, and thus other factors may have a greater influence on chlorophyll variability.

An interesting point here is that this mode has a decadal variability, as shown in the time series (Fig. 5c). We found that this variability is related to Pacific Decadal Oscillation (PDO). In fact, the 2 time series of chlorophyll and TC frequency mode coincide well with the 3-year running averaged PDO index (bold line in Fig. 5c). They are also significantly correlated with the high-frequency variability of the PDO index. The correlation coefficients between the original monthly PDO index and the 2 time expansion coefficients of chlorophyll and TC frequency were 0.88 and 0.79 , respectively. These results imply that the PDOinduced variability of TCs may be one of the key mechanisms regulating the amount of phytoplankton biomass in the WNP basin.

\section{Summary and discussion}

Due to the lack of reliable and spatially unlimited chlorophyll data, the basin-wide and long-term scale relationship between TCs and phytoplankton had not been previously explored. By using $>12$-years of satellitederived chlorophyll concentrations and the RSMC best track data of TCs, the long-term relationship between chlorophyll concentrations and TC tracks has been investigated in this study. This is the first climatic study analyzing the relationship between biomass and TC activity in the WNP. We found that despite short-term effects of a single TC on marine biology, the long-term change of phytoplankton in the WNP is significantly associated with the long-term variability of TC frequency. This result could dispel the common belief that TCs have a negligible effect on the long-term variability of phytoplankton, and we suggest that TC variability should be considered in the estimation of chlorophyll, even in the long-term scale.

One might argue that the physical mechanism of TC 
influence on marine biomass in the long-term scale is still vague, because the response of phytoplankton lasts less than a month after passage of the TC. However, the point addressed in this study is not that the memory of phytoplankton response to TCs is prolonged over the seasons, but rather that the interannual variability of TCs is highly related to a similar variability of phytoplankton anomalies in the WNP. This result could be particularly meaningful for identifying the climatic relationship between TCs and marine phytoplankton, and also for providing a possibility of more accurate estimation of the primary production in the long-term scale.

The analysis of co-variability of the 2 bio-physical systems showed that PDO is behind such a relationship. According to previous studies on TCs in the WNP, the decadal variability of TC tracks may be attributed to the PDO signal (Liu and Chan 2008; Kubota and Chan 2009). That is, PDO is the phenomenon affecting sea surface temperature (SST) variation in the WNP, and it could modify circulation over the WNP by altering the meridional gradient of SST. This modified circulation can change the track and the formation of TCs, and consequently affect the ocean phytoplankton.

As mentioned in previous studies, El Nino may also induce a TC frequency pattern similar to that in Fig. 5b (Elsner and Liu 2003; Camargo et al. 2007). That is, the TC track tends to shift eastward when an El Nino event occurs, while tracks westward during La Nina. However, the TC track can also be affected by many mid-latitude factors such as wind shear, SST in the subtropics, and large-scale atmospheric patterns, and those factors are also linked to mid-latitude-tropical interactions. Therefore, it is difficult to conclude that there is only one phenomenon controlling the co-variability of chlorophyll and TC activity. Nevertheless, statistical evidence shows that the relationship between the expansion coefficients in Fig. 5c and the PDO index is stronger than that with the ENSO index (such as NINO3 or NINO4).

Another important point to consider is the chlorophyll variability associated with $\mathrm{TC}$ activity during a warming climate. Recent investigations on TCs in a warming climate reveal that measurements of TC activity, such as intensity, genesis, and passage track, are expected to change, being accompanied by variations in SST, static stability, low humidity, and vertical wind shear (Emanuel 2005; Webster et al. 2005; Bengtsson et al. 2007). The WNP is a region where TC activity is acknowledged to be strong and the corresponding biomass variability is significantly affected by TCs, as presented in this study.
Therefore, in a warmer climate, TC influence on the ocean phytoplankton should be changed, which can be applicable for adaptation to climate change. For this reason, the biological response to TCs on a long-term scale should be included in climate modeling. Furthermore, from a bio-geophysical point of view, the feedback effect produced by TC-driven phytoplankton should also be an area for future research.

\section{Acknowledgement}

This work was supported by the Korea Meteorological Administration Research and Development Program under grant CATER 2010-2209.

\section{References}

Babin SM, Carton JA, Dickey TD, Wiggert JD (2004) Satellite evidence of hurricane-induced phytoplankton blooms in an oceanic desert. J Geophys Res 109:C03043. doi:10.1029/2003JC001938

Bengtsson L, Hodges KI, Esch M, Keenlyside N, Kornblueh L, Luo JJ, Yamagata T (2007) How may tropical cyclones change in a warmer climate? Tellus A 59(4):539-561

Camargo SJ, Robertson AW, Gaffney SJ, Smyth P, Ghil M (2007) Cluster analysis of typhoon tracks. Part II: largescale circulation and ENSO. J Climate 20:3654-3676

Campbell JW (1995) The lognormal distribution as a model for bio-optical variability in the sea. J Geophys Res 100(C7):13237-13254

Dickey T, Simpson J (1983) The sensitivity of upper ocean structure to time varying wind direction. Geophys Res Lett 10(2):133-136

Elsner JB, Liu KB (2003) Examining the ENSO-typhoon hypothesis. Climate Res 25:43-54

Emanuel K (2005) Increasing destructiveness of tropical cyclones over the past 30 years. Nature 436(7051):686688

Esaias WE, Abbott MR, Barton I, Brown OB, Campbel JW, Carder KL, Clark DK, Evans RH, Hoge FE, Dordon HR, Balch WM, Letelier R, Minnett PJ (1998) An overview of MODIS capabilities for ocean science observations. IEEE Geosci Remote S 36(4):1250-1265

Hazelworth JB (1968) Water temperature variations resulting from hurricanes. J Geophys Res 73:5105-5123

Kim JH, Ho CH, Sui CH, Park SK (2005) Dipole structure of interannual variations in summertime tropical cyclone activity over east Asia. J Climate 18(24):5344-5356

Kubota H, Chan JCL (2009) Interdecadal variability of 
tropical cyclone landfall in the Philippines from 1902 to 2005. Geophys Res Lett 36:L12802. doi:10.1029/ 2009GL038108

Kwon M, Jhun JG, Ha KJ (2007) Decadal change in east Asian summer monsoon circulation in the mid-1990s. Geophys Res Lett 34:L21706. doi:10.1029/2007GL031977

Lee D, Niiler P (2003) Ocean resonse to typhoon Rusa in the south sea of Korea and in the East China sea. J Korean Soc Oceanogr 38(2):60-67

Lin I, Liu WT, Wu CC, Wong GTF, Hu CM, Chen ZQ, Liang WD, Yang Y, Liu KK (2003) New evidence for enhanced ocean primary production triggered by tropical cyclone. Geophys Res Lett 30:1718. doi:10.1029/2003 GL017141

Liu KS, Chan JCL (2008) Interdecadal variability of western North Pacific tropical cyclone tracks. J Climate 21(17): 4464-4476

McClain CR, Cleave ML, Feldman GC, Gregg WW, Hooker SB, Kuring N (1998) Science quality SeaWiFS data for global biosphere research. Sea Technol 39(9):10-16

McGillicuddy DJ, Robinson AR, Siegel DA, Jannasch HW, Johnson R, Dickeys T, McNeil J, Michaels AF, Knap $\mathrm{AH}$ (1998) Influence of mesoscale eddies on new production in the Sargasso Sea. Nature 394(6690):263266

Moore JK, Abbott MR (2000) Phytoplankton chlorophyll distributions and primary production in the Southern Ocean. J Geophys Res 105(C12):28709-28722

Sanford TB, Black PG, Haustein JR, Feeney JW, Forristall GZ, Price JF (1987) Ocean response to a hurricane. PART 1: Observations, J Phys Oceanogr 17(11):20652083

Smith TM, Reynolds RW, Peterson TC, Lawrimore J (2008) Improvements to NOAA's historical merged land-ocean surface temperature analysis (1880-2006). J Climate
21(10):2283-2296

Son SH, Platt T, Bouman H, Lee DK, Sathyendranath S (2006) Satellite observation of chlorophyll and nutrients increase induced by Typhoon Megi in the East/Japan Sea. Geophys Res Lett 33:L05607. doi:10.1029/2005GL025065

Stramma L, Cornillon P, Price JF (1986) Satellite observations of sea surface cooling by hurricanes. J Geophys Res 91(C4):5031-5035

Subrahmanyam B, Rao KH, Rao NS, Murty VSN, Sharp RJ (2002) Influence of a tropical cyclone on Chlorophyll-a Concentration in the Arabian Sea. Geophys Res Lett 29:2065. doi:10.1029/2002GL015892

Uz BM, Yoder JA, Osychny V (2001) Pumping of nutrients to ocean surface waters by the action of propagating planetary waves. Nature 409(6820):597-600

Walker ND, Leben RR, Balasubramanian S (2005) Hurricaneforced upwelling and chlorophyll a enhancement within cold-core cyclones in the Gulf of Mexico. Geophys Res Lett 32(18):L18610. doi:101029/2005GL023716

Webster PJ, Holland GJ, Curry JA, Chang HR (2005) Changes in tropical cyclone number, duration, and intensity in a warming environment. Science 309(5742): 1844-1846

Zhao H, Tang DL, Wang DX (2009) Phytoplankton blooms near the Pearl River Estuary induced by typhoon Nuri. J Geophys Res 114:C12027. doi:10.1029/2009JC005384

Zheng GM, Tang DL (2007) Offshore and nearshore chlorophyll increases induced by typhoon winds and subsequent terrestrial rainwater runoff. Mar Ecol-Prog Ser 333:61-74 